This is a peer-reviewed, accepted author manuscript of the following research article: Hewitt, A. (2005). Teachers' personal construct models of pupil individuality and their influence in the music classroom. Music Education Research, 7(3), 305-330.

https://doi.org/10.1080/14613800500324416

\title{
Personal Construct models of pupil individuality and their influence in the music classroom.
}

Revision for Music Education Research, submitted $31^{\text {st }}$ March 2005

Word count: 8,346 (excluding abstract and references)

\section{AUTHOR NOTE}

Correspondence concerning this article should be addressed to Dr Allan Hewitt, Department of Creative \& Aesthetic Studies, Faculty of Education, University of Strathclyde, 76 Southbrae Drive, Glasgow, G13 1PP. Email address: allan.hewitt@strath.ac.uk

Allan Hewitt is Lecturer in Music in the Faculty of Education, University of Strathclyde, Glasgow, Scotland. He has professional experience as a performer, composer and educator. Current research is focussed on the areas of children's composing and the self-theories of student musicians. 


\begin{abstract}
This paper reports an investigation of the belief patterns of music teachers with regard to the nature and significance of factors of individual difference in the context of secondary school classroom music teaching. Belief patterns were collected in the form of Personal Construct models, drawing on Kelly's Theory of Personal Constructs [Kelly, G. 1955 \#1257]. The study explored both music teachers' Personal Construct models of pupil individuality and the reported significance of those models of pupil individuality for the participants' teaching approaches. The investigation of Personal Construct models analysed both how each participant grouped pupils they teach according to perceptions of individual difference and how the belief patterns of participants compared with each other.
\end{abstract}

The study involved eight secondary school music teachers working in the West of Scotland. Participants' construct models were elicited using Repertory Grid technique, where pupils were grid elements and factors of individual difference the constructs. The influence of models of individual difference on classroom practice was then investigated using semi-structured interviews.

Three main findings from the study are discussed. Firstly, there was considerable variation among participants in the choice of factors of individual difference believed to be significant for teaching in music, and therefore in their Personal Construct models. Secondly, there were notable similarities in how participants appeared to group sets of pupils within those models, even though the models 
themselves varied widely. Finally, Personal Construct models and specific belief patterns relating to individual differences appear to be important influences on the structure and nature of teaching in music. 


\section{INTRODUCTION}

Teachers' beliefs about what constitutes effective classroom practice and the nature of learning have received considerable attention from the educational research community over the last thirty five years. Much of this research is predicated, at some level, on the understanding of teachers' beliefs as an important component in understanding their behaviour in the classroom. This contention, that to fully understand behaviour we must first uncover the reasons behind it, is clearly based on an assumption that behaviour and belief are causally related [Munby, H. 1982 \#1037]. Researchers have therefore proceeded on the understanding that the beliefs they were eliciting and theorising were a partial, if not the whole, basis of teacher behaviour [Kagan, D. M. 1992 \#722].

Segal [Segal, 1998 /d], for example, has argued that teachers achieve a sort of balance, or compromise, between their possibly idealistic beliefs and their actual practice. Beliefs, he suggests, develop from the formulation of effective responses to the stress, fear and uncertainty that the new teacher faces. Over time, these survival responses grow into deep-rooted beliefs and attitudes about teaching and about pupils and, as Schutz [Schutz, 1971 /d] has observed, tend to be fairly stable over long periods of time. This stability is often reinforced by the collective experience of the staff in a particular school such that a particular set of beliefs and attitudes becomes the 'norm' for those teachers working in that school [Parsons, Graham \& Honess, 1983]. 
The importance of investigating teachers' beliefs as a complement to researching their behaviour arose, in part, from dissatisfaction on the part of some researchers with the positivist, observational approach exemplified in educational research through the 1960's and early 1970's. It was, to some degree, a reaction against the kind of approach exemplified, for example, in the observational anthologies of Simon and Boyer (1974) and Galton (1978). As researchers began to investigate specific areas of teacher behaviour such as their decision-making or their planning processes, it became clear that a more fundamental investigation into what teachers actually thought and believed would be a useful addition to the research (Clark \& Yinger, 1977; Clark, 1980). Significantly, this reflected a growing interest in the causes of difference between various teachers; investigation into teacher beliefs came to be viewed as an important way in which such differences could be explained (Clark, 1980; Shavelson \& Stern, 1981).

Some authors (Clark, 1986; Clark \& Florio, 1983; Posner, Strike, Hewson, \& Gertzog, 1982) have suggested that research on teachers' beliefs can also have a significant impact on the way that researchers themselves think about teaching and on the perceived relationship between educational researchers and practitioners. Initial work attempted to go some way to explaining why teachers operate as they do and to improve practice by suggesting ways in which change and innovation could be better implemented. It has been argued that this effected an increase in understanding, and has gradually moved educational researchers' conceptions of teaching from a "strange and unfamiliar land" (Clark, 1986: 14) to 
one in which they feel able to offer suggestions and advice, for example in using research to inform the design of curricula.

Research into teachers' beliefs has also been found useful in the context of informing teacher education programmes. Research into the interface between actual practice and the training process, for example, has been informed by investigations into the cognitive aspects of teaching (Macleod \& McIntyre, 1977). Shavelson \& Stern (1981) have suggested that such research supports the development of 'coherent prototypes' that allow the interface between intention and behaviour to be explored and analysed by students.

It is therefore clear that, historically, research into teachers' beliefs has held an important place within the broad spectrum of educational research. It is unfortunate, therefore, that relatively little empirical work has involved music educators and their particular concerns. As has been suggested elsewhere, it is vital that this type of empirical inquiry be explored against the unique cultural and sociological context of music education, given the potential impact of a teacher's philosophical beliefs on their classroom practice (Jorgenson, 1990). One of the few exceptions to this is Brandstrom (1999), who has explored music teachers 'everyday' conceptions of what constitutes 'musicality' and how this impacts on their practice. A greater number of studies have explored the beliefs and attitudes of music educators in the pre-service phase of their careers, including Campbell et al (1996), who describe various belief models about the purpose of music education. Russell (1996), in her analysis of excerpts from a student's journal, 
describes one trainee teacher's belief models about teaching. Other studies [Hennessy, 2000 /pt “e.g."] have sought to explore trainee teachers' attitudes towards specific areas of the music curriculum.

Studies in beliefs and attitudes can, of course, cover an enormous range of foci, including effective teaching, resourcing issues, subject knowledge and so on. The purpose of the study reported in this paper was to specifically focus on music teachers' beliefs relating to both the nature and the significance for classroom practice of perceived individual differences among pupils. 'Individual differences' were defined as distinguishing characteristics which vary between pupils, and which may have some influence on the learning and teaching process. A wide range of such differences have been identified as performing such a role, including confidence, motivation, gender, socio-economic status, learning style and so on (Tyler, 1965; Howe, 1998; Oosterheert \& Vermunt, 2001).

No published research has been done into practising music teachers' beliefs about these differences, either in terms of how pupils are believed to differ from each other or the influence that perceptions of difference may have on the learning and teaching process in music. The study reported here followed on from a wider and cross-subject investigation into the belief patterns of teachers with regard to the nature and significance of factors of individual difference in the context of secondary school classroom teaching (Hewitt, 2002). The primary aim of this study was to elicit the characteristics of individual difference that music teachers 
believed to be important and to explore the perceived significance of those differences for the participants' classroom practice.

The theoretical model adopted to investigate music teachers' beliefs on this topic was that of Personal Construct theory, introduced by George Kelly (1955) and subsequently used in a number of studies in music education to allow viewpoints and attitudes to be collated and described in a systematic fashion (e.g. Mellor (1999), who used the approach to explore how music teachers think about children's compositions). Individual participant's Personal Construct models were taken to be representative of how they viewed the topic of individual differences with reference to their pupils. Further background to the method is provided later in the paper.

\section{METHODOLOGY}

\section{Participants}

The study involved intensive cooperation from eight participants, all of whom were classroom music teachers working in secondary schools in the West of Scotland. The group comprised five males and three females with a range of teaching experience ranging from four to just over twenty years. Five participants held promoted posts within the Music department in their schools. Participants were self-selecting following an open invitation to staff in 66 secondary schools in 
the West of Scotland area. The participants are identified within this paper as 'Participant A' to 'Participant H'.

\section{Data collection}

Each participating teacher visited the Faculty of Education at the University of Strathclyde for either a morning or afternoon session. An average session lasted around three hours and involved two main activities, (1) the completion of a computer-based Repertory Grid which formed the Personal Construct model and (2) a semi-structured interview. Each activity lasted around 1.5 hours.

The Repertory Grid tool was used as it is a well established method for developing Personal Construct models, exploring how individual participants view, or 'construct', particular activities or contexts. It is a cognitive mapping technique that attempts to describe how people think about the phenomena in their world (Tan \& Hunter, 2002). The tool is based on Personal Construct theory, which pictures the individual as a scientist who develops hypotheses (or constructs) that provide a model of how the world works. The creation of a Repertory Grid requires participants to name a range of 'elements' that represent the topic of interest, and then to formulate a range of 'constructs' that are ways in which these elements are thought to differ from each other. So, for example, a researcher who was interested in finding out how people differentiate between different types of car might ask them to name a few cars (their 'elements') and then describe the ways in which, to them, those cars are different. The 
differences become the 'constructs'. The combination of elements and constructs forms a 'grid' that is then analysed for clustering patterns. Of particular interest are the ways that certain elements are clustered around certain constructs, which is believed to inform the researcher of how the participant understands the broader phenomena. In this study, the elements in each participant's grid were pupils currently or previously taught by the participant, and the constructs were ways in which these pupils were believed to differ from each other that might influence the participant's teaching approach with them.

The elicitation process, where participants named their elements and identified salient constructs, was carried out using the RepGrid software package running on an Apple Macintosh computer. Participating teachers were encouraged to physically enter their data with the researcher sitting to one side, providing verbal cues and instructions. In order to establish the context for the selection of elements (pupils' names), the request was to enter "pupils you currently teach or have taught in the past". Participants were told that they could select pupils from any stage of the secondary school.

The RepGrid package requires the researcher to initially enter a context question that forms the basis of the grid elicitation. This took place before the participating teachers arrived. In keeping with the purpose of the study, the question used was "in what way, which you consider to be important in terms of learning and teaching, are two of these pupils alike and the other different?" This question was 
clearly visible on the computer screen throughout the elicitation process and proved useful in maintaining the focus on the precise purpose of the process.

When each participant had entered a selection of pupil names, the process moved on to the elicitation of the constructs. In keeping with established guidelines on the Repertory Grid procedure (e.g. Fransella \& Bannister, 1977) and as recommended by its originator George Kelly (1955), the triadic procedure for construct elicitation was used. This involved the computer randomly selecting and presenting on screen three pupil names from which the participant selected one who was different in some way from the other two. The difference upon which this decision was made formed the new construct, which in turn represented the individual difference.

Following the elicitation of the construct (e.g. "socio-economic status"), all of the pupils were rated on the construct. This rating took place on a five-point high to low scale which was visually represented as a vertical pole on the computer screen. Each pupil was rated on every construct to produce a grid. This process of construct elicitation continued until it appeared that the participating teacher was unable to produce further differences between pupils that were meaningful to them. At this point, the participant's Personal Construct model of their pupils' individuality was complete.

The second phase of the study began at the conclusion of elicitation. The completed Personal Construct model, in the form of the element-construct grid, 
was presented to the participant and formed the basis of a semi-structured interview in which the practical significance of particular constructs was explored. This interview involved the researcher and the participating teacher looking at the visual representation of the grid and discussing each of the elicited constructs. The main probing question used for each construct was "in what ways does your awareness of differences between your pupils on this construct influence how you would teach them?" Subsequent probes were designed to elicit information about how the teacher's awareness might be reflected in the nature and/ or structure of teaching activities, or on variations in expectations that the teacher might have. The interviews were recorded on minidisk and subsequently transcribed for analysis.

This mixed-methods approach was believed to be appropriate as it allowed the researcher to investigate both the Personal Construct model of each participant and to relate that model to the participant's classroom practice. In doing so, a more complete picture of the topic was gained than would have been the case had only one approach been taken.

\section{Data analysis}

Analysis was in two stages, the first of which was a quantitative analysis of the model grid data and the second a thematic analysis of the interview transcripts. Four statistical procedures were applied to the data within SPSS. Firstly, a set of descriptive statistics was produced for elements and constructs in each grid, 
including the mean rating and range for each. Secondly, a Hierarchical Cluster Analysis (HCA) was applied both to elements and to constructs within the grid. The aim of the HCA procedure was to evaluate how participants appeared to cluster elements and constructs. In order to investigate this, HCA was used on both element and construct data and output in the form of dendrograms. These were useful tools in analysing cluster patterns within the grid.

Following the HCA procedure, a Proximity Matrix (PM) based on dissimilarity between elements and between constructs was produced on the basis of Euclidean distance. The matrix provided a useful support for HCA data, which was analysed by observation, and added clarity to the analysis of the relationship between various constructs and elements. It should be noted that these procedures did not produce identical results, but the pattern suggested in the HCA was always supported by the information in the Proximity Matrix. On some occasions, for example, individual elements or constructs were found to have low levels of dissimilarity in the PM while being part of different clusters within the HCA. Throughout the analytical process, every attempt was made to utilise both procedures in order to arrive at a satisfactory explanation of the data.

Finally, data for constructs within each grid was subjected to Principal Components factor analysis with Varimax rotation. A preliminary analysis identified whether two or more factors had eigenvalues greater than 1.00. Where this was not the case, factor extraction was repeated with the instruction to extract 
two factors. Loading of constructs on each component was examined, and observations are reported below.

The statistical analysis of grid data was complemented by analysis of the transcripts of semi-structured interviews in which participants discussed the significance for their classroom practice of the various individual differences they had identified within their Personal Construct model. Analysis was based on the coding and synthesis of salient themes and sub-themes, as outlined in Miles \& Huberman (1994). Information relating to each construct was extracted and a selection is reviewed below.

\section{RESULTS OF STATISTICAL ANALYSIS OF PARTICIPANTS' REPERTORY GRIDS}

\section{Inter-participant analysis}

The inter-participant analysis treated the dataset as a whole, comparing the Personal Construct models of each participating teacher with the rest of the group. The first step in synthesising the separate constructs was to sort the construct labels into three semantic categories using an iterative procedure. Ninety-one constructs were sorted in this way, and a summary of categories and frequency of occurrence for each construct is presented in Table 1.

(Insert Table 1 about here) 
A summary of the contributions to particular categories of individual participants is presented in Table 2 .

(Insert Table 2 about here)

The majority of constructs elicited were categorised as cognitive, affective and social. These were factors of individual difference that result from non-musical and non-contextual aspects of the pupil's character. Constructs such as 'academic ability', 'behaviour', 'motivation' and so on were typically used. It was notable that these generic factors of difference received far more attention than subjectspecific factors, which were allocated to the 'musical' category. This suggested that participants were less concerned with subject-related abilities, such as talent and skill in the case of music, and more with factors that may have greater stability across subject disciplines. In other words, participating teachers may have been less inclined to view pupils in terms of their relative merits in their particular subject, and perceived less likelihood of such differences shaping and directing the manner in which they approach teaching those pupils. This finding supports that resulting from a Q-sort analysis of music teachers' attitudes towards individual differences (Hewitt, 2003).

The music-related differences elicited from participating teachers were fairly limited in range, being mainly concerned with perceived differences between pupils in talent, ability, and skill. A distinction was drawn by many participants between musical 'ability' (which they considered innate and therefore well- 
established) and musical 'skill', which was considered more susceptible to intervention by the teacher. In all cases, however, musical factors of difference were conceptualised as ways in which certain pupils would be able to achieve a higher standard of outcome than pupils who lacked such attributes. During followup interview, these factors appeared to have relatively little direct influence on actual teaching approaches and methods, but significant indirect influence.

Finally, there was considerable variety in the importance given by participants to contextual factors within Personal Construct models. This was observed in the variation in percentage of occurrences of constructs in this category in Table 2 . Participants who contributed contextual factors as part of their grids tended to focus on the negative influence of factors such as socio-economic status or lack of parental support, suggesting that these were characteristics outwith the teacher's control but which could have a significant effect on the degree to which other factors, such as confidence and motivation, were present within the individual pupil.

Given the range of constructs elicited, only a selection of the most frequently elicited constructs are discussed in the context of the interview analysis presented later in this paper. One of the strengths of the Repertory Grid technique, however, is that it generates a significant amount of quantitative information that can be subjected to statistical analysis. The results from this process, as applied to each individual Personal Construct grid, are described in the following section. 


\section{Intra-participant analysis}

Intra-participant analysis, unlike the inter-participant analysis outlined above, focussed only on the model grid data collected from each participant. There was no attempt to draw comparisons between the eight grids, rather the focus was on each participant's Personal Construct model of pupil individuality. The following is an illustrative example of the statistical analysis that was applied to each of the eight grids. In this case, the data was gathered from participant D. A summary of the analysis of the remaining grids is presented in Table 7.

As part of his Personal Construct model, Participant D identified ten constructs as characteristics of individual difference between the pupils (the 'elements') who were included in his grid. These were allocated to the three semantic categories as indicated in Table 3. It was observed that almost all constructs, with one exception, were allocated to the cognitive, affective and social category. The remaining construct was subject-specific.

(Insert Table 3 about here)

The Hierarchical Cluster Analysis of the grid, represented as a dendrogram in Figure 1, suggested that Participant D grouped his pupils around three clusters. After examination of the rating patterns for these clusters, some judgments were made of their particular characteristics (Table 4). 
(Insert Figure 1 about here)

(Insert Table 4 about here)

Moving from elements to constructs, Hierarchical Cluster Analysis on the elicited constructs in the grid produced two clusters involving six of the ten constructs (Figure 2). These clusters were indicative of ways in which Participant D rated his pupils similarly. Cluster one, for example, included musical fluency, the ability to inspire others, and speed of learning. Cluster two included ability to communicate, motivation, and confidence. Generating a Proximity Matrix for constructs and comparing visual observations with the mean dissimilarities in the matrix substantiated these interpretations.

(Insert Figure 2 about here)

In the Proximity Matrix, greatest dissimilarly between ratings on constructs was found in the constructs 'independence in learning' (mean dissimilarly=5.3), 'level of parental support' (mean dissimilarity=4.9) and 'level of organisation in learning' (mean dissimilarity $=4.8$ ). The separation between these constructs and the two clusters identified previously was observed in Figure 2. This was noted, for example, in D's rating pattern for Gemma and Lorraine. Both pupils scored highly in most constructs, but low on 'independence in learning'. This suggested that this particular construct offered a useful way, for Participant D, of differentiating between these two pupils. Finally, Principal Components 
Analysis (PCA) with Varimax rotation was applied to the construct rating pattern for the grid. One component was found to account for around $73 \%$ of the variance of the grid. A further component accounted for around $10 \%$ of the total variance. Loadings of the various constructs on these components are outlined in Table 5.

(Insert Table 5 about here)

Finally, the pattern of loading in the grid was summarised as outlined in Table 6, along with an exploratory interpretation of factor loading.

(Insert Table 6 about here)

In this example, 'level of independence in learning' did not load significantly on either component although, in keeping with the exploratory interpretation of factors outlined above, the fact that it loaded more heavily on component two was to be expected.

\section{Results from the remaining grids}

Table 7 provides a summary of the analysis of all eight grids elicited from participants during this phase of the study.

(Insert Table 7 about here)

From this analysis, considerable similarity in the grouping patterns of the participating teachers was observed in that they appeared to follow a high- 
middle-low construction. While there were situations in which a single construct separated clusters of pupils, it was often impossible to identify one shared construct that accounted for this differentiation across the grids. When the role of constructs in differentiating pupils was investigated by means of cluster and dissimilarity analysis, there was again little apparent consistency in what constructs provided greatest distinction between pupils. Some constructs, such as 'enjoyable to teach', 'determination to succeed'/ 'motivation' and 'level of parental support' were found in this category on several occasions. This suggested that participants might differentiate pupils on an idiosyncratic basis, with little commonality between them. Factorial analysis tended to support this view, where components accounting for variance in grids were identified but could not readily be categorised into a common framework. For most participants it was possible to distinguish salient features of the first and second components, but those features were not subsequently replicated in the analysis of other Personal Construct models. Indeed, socio-economic status was the only factor to consistently emerge as an important characteristic underlying variance in music teachers' evaluations of their pupils.

\section{RESULTS OF ANALYSIS OF SEMI-STRUCTURED INTERVIEWS}

The purpose of the study was not only to investigate the Personal Construct models and the range of constructs used by music teachers to differentiate between pupils, but to explore the ways in which those constructs were believed by teachers to be influential in shaping and informing their teaching approaches 
in music. After completing the process of model elicitation, therefore, participants were asked to describe the particular significance for their approach to teaching of the various constructs they had identified. When the interview transcripts were analysed each construct was allocated to one of the three semantic categories initially developed during the quantitative analysis of grid data (Cognitive, affective and social, Musical, and Contextual). In the following section, responses drawn from each category are reviewed. The discussion is selective rather than exhaustive, including salient comments and features of teachers' responses that contribute to an overall understanding of the nature of the significance of individual factors of difference for classroom music teaching.

\section{Semantic category 1: 'Musical constructs'}

As noted in the previous section, subject-specific constructs appeared with less frequency than might have been expected. However, a number of factors of this type were elicited, and participants' beliefs relating to their significance for teaching are outlined below.

\section{Musical fluency}

For one participant, the possession of 'musical fluency' by a pupil ensured that they were capable of a more accurate perception of rhythm and pitch. For classroom practice, this was of greatest significance in performing work, where the teacher was required to intervene less where fluency was higher. Pupils who lacked musical fluency were described as frequently requiring 'low level' 
support in the context of being told 'how it goes', and were believed to lack the ability to regulate and monitor their own progress during private practice on an instrument.

The importance of musical fluency extended into higher-order aspects of musical performance, as pupils with greater musical fluency would tend to take the initiative in developing interpretive and aesthetic features of performance. Where the pupil with low musical fluency might require significant assistance from the teacher, pupils with high fluency levels could, again, be trusted to make such judgments by themselves.

Finally, another participant identified the ability to 'play with style' as being related to the possession of high levels of musical fluency. This again removed an aspect of support requirement from the teacher, and was believed to result in a more satisfactory level of performance.

\section{Musical skill}

Musical skill was also significant for several participants. One stressed that musical skill was a fundamentally different quality from intellectual ability. Intellectual skill could, however, compensate for lack of musical skill;

People say to me, 'your kids are really musical'. Sometimes they're intellectual, they can get 'A' passes, but I don't consider them to be musical. Innate musical skills are different from... with Kier, he's got an 'A' pass, but he's not musical...

\section{Musical ability}


A third subject-specific construct used by several teachers was 'musical ability'. This could be contrasted with previous concepts of fluency and technical skill in that it may be more concerned with something innate and subconscious in terms of execution, and perhaps as a result be less susceptible to influence by the teacher. One participant suggested that musical ability was one of the most influential individual differences in the classroom, as many of the other factors (such as confidence, motivation, independence) were predicated to a large extent on the level of subject-based ability individual pupils possessed.

For another teacher, the possession of a high level of musical ability allowed the teacher to allow for an increased sense of personal responsibility for learning; "It means you can leave them alone and you don't have to spend a lot of time on it". Here, the participant assumed that there was a more sophisticated and deeper understanding of the particular task, which in turn allowed the pupil to engage with the task while requiring less support than a pupil who lacked such background of ability.

Another participant suggested that, in situations where the teacher was aware that the pupil possessed a high musical ability, they were able to draw on this general (and possibly transferable) ability where the pupil faced particular challenges. This was discussed with the interviewer in the context of the model of the 'general musician' used as the basis of the music curriculum in Scotland, where pupils are expected to become competent in a variety of different musical disciplines (e.g. 
composer, performer, analyst, commentator).

It was found in several cases that this model contradicted the 'professional' approach to music, where individuals will generally specialise in one discrete area of work. Was it right, the interviewer asked one participant, to expect school pupils to have this 'all-round' ability in music? The teacher replied; "there are very few people who I've taught who I would say were good at everything". They went on to describe music as "such a huge subject", noting that even within particular disciplines such as performing there are varieties of subsets (e.g. traditional music) that require quite different kinds of skills to be properly undertaken. For another participant, variations in musical ability primarily influenced teacher expectations rather than the practical organisation of teaching;

The impact of that is expectation, I think. I expect different things from some pupils than others. Two pupils can come out with the same mark in a listening paper, with one I might say 'well done' whereas with the other it might be 'you could have done better'. So it's about expectations of how they will get on.

When this participant was asked whether pupils with high levels of musical ability were 'easier' to teach, they replied that there was less significance for practical teaching purposes in the level of ability, and more significance in the spread of ability within the class. In other words, a class in which all the pupils were of low musical ability was seen to be easier to teach than a class where there was a variety of ability levels present. 
However, the participant did agree that pupils with high levels of musical ability tended to be more interested and motivated; teaching became more challenging and more rewarding because, to some extent, the teacher was being challenged to draw on their specialist skills and knowledge in a way that was absent when dealing within pupils of lower musical ability.

\section{Musical interests and preferences}

The development of the music curriculum in Scotland over the last fifteen years has received considerable comment, not least in the expansion of range of musical styles and genres being explored and performed by pupils in the secondary school (Sheridan, 1999). For one participant the particular expertise or interest a pupil had in terms of musical genre could be a significant factor of individual difference that would influence their teaching approaches. As they explained, teachers have to "deal with all the many different musical interests that the kids come with". The teacher discussed the issue in terms of their own lack of experience in certain styles. The identification of an area of weakness in their own skills involved this participant in an attempt to address the situation by gaining the necessary insight and advice to address the needs of the pupil.

Well, I think it's been a learning curve for me as well. I'm a classical musician, classically trained, and I've had to find out different ways to adapt my teaching to cope with many different people who are doing, particularly certificated music, employing all kinds of strategies.

It was unrealistic, they argued, to expect teachers to be able to effectively teach all the possible range of sub-types and specialisms that are possible when there are 
no stylistic boundaries to what pupils can do. As a teacher, they explained, they had to realise where their strengths lay, and "draw the line somewhere" in terms of what they allowed pupils to do.

You have to bear in mind that they have expertise and specialists in one particular area as well, and you can't expect them to be expert in everything unless you are prepared to put in enormous resources in terms of in - service and training.

\section{Involvement in extra-curricular activities}

Involvement in musical extra-curricular activities was identified as being a significant factor that differentiated pupils. Significance for learning and teaching was defined in two ways. First, it encouraged better relationships between the teacher and the pupils who were involved in such activities as compared with those who were not. Not only were these relationships formed between teacher and pupil, but there was also the possibility that a closer bond could be formed with the pupil's family through participation and attendance at concerts and other musical events. Participant B insisted that this significantly helped them teach the pupils, because there was greater freedom of communication and often a more effective dialogue with the parents. Secondly, participation in such activities was believed to result in pupils spending greater quantities of time in the Music department, thereby providing additional opportunities for interventions and further assistance in situations where this was deemed necessary by the teacher. 


\section{Degree of music in background}

One participant had identified 'degree of music in background' as one of their constructs during grid elicitation. On further exploration, it was found that they used this construct to differentiate those pupils whose home backgrounds were characterised by having high levels of musical content, usually involving parents who listened to music in the home, or who themselves were involved in musicmaking activities. In such cases the participant suggested that they would expect higher levels of practice outwith the formal timetable because there would be increased parental pressure on the pupil for this to occur. This in turn would ensure more rapid progress through repertoire, and lessen the requirement for the teacher to provide such motivation. It would also have the benefit of providing the pupil with exposure to different styles and genres of music, and therefore provide the kind of experience where delivery of the listening element in music would be easier for the teacher because there was already some level of knowledge.

\section{Semantic category 2: 'Cognitive, affective and social factors'}

Seven factors were identified within this category. Salient aspects that emerged during interview analysis are presented below.

\section{Speed of learning}

One participant identified 'speed of learning' as being a factor, significant for their teaching, which varied between pupils. This factor was believed to affect the rate at which pupils progressed, both in terms of single tasks or activities and in 
the more general context of a level or programme. Variations in pace were reported to require the teacher to ensure that there were sufficient and adequate materials and resources to address the needs of all pupils, regardless of rate of progress.

\section{Degree of requirement for on-going support}

Participants also identified variations in the level of support individual pupils needed to complete a task successfully. This required the teacher to make critical decisions about how best to spend their time, who to work with, and how best to support each pupil requiring assistance. It could, one participant suggested, have time-consuming implications in the context of additional resource preparation, and the need to co-ordinate approaches with other involved parties such as classroom assistants and learning support teachers. However, the same participant felt it was critical that the pupil requiring more extensive support received all possible help, regardless of the additional burden on the teacher.

\section{Level of organisation and degree of independence in learning}

Participants also identified a number of ways the degree to which a pupil was able to self-organise their work would influence the teaching process. Most significant was the level of independence that could be given to the pupil, in terms of the pace of learning, organisation of material, keeping progress records and planning next steps. Pupils with high-level organisation skills were also allowed significant responsibility in terms of choices of instruments, resources and so on. In all of these, there were elements of what would usually be considered the teacher's 
responsibility apparently being passed to the pupil, thereby lightening the load for the teacher and empowering the pupil. This construct therefore appeared to be, for certain participants, an important way in which pupils differed and one that allowed them to engage in "consistently good quality of teaching and rapport with pupils". One participant suggested that low levels of independence in learning were usually related to low levels of confidence and self-esteem;

...it's not that they don't understand what they're doing, they constantly have to check that what they're doing is right.

She went on to outline tasks used in the music classroom that involved the pupils in considerable amounts of group-based, critical thinking work. Such tasks, she suggested, would be far better suited to those pupils who possessed high levels of independence, given that the basic purpose of the task was to draw on the ability of pupils to work together, without the assistance of the teacher.

In the context of learning a musical instrument, another participant argued that the ability to work alone was essential for the young musician. There was "no way" the teacher could be expected to provide constant input in this activity, given the need to attend to large numbers of pupils simultaneously. Therefore, those pupils who could use the time for private practice productively were likely to make faster and better progress than those who found self-directed study problematic.

\section{Level of ability to communicate about learning}

The ability of the individual pupil to give feedback about various aspects of their learning appeared to be a significant factor for some participants. One 
participant suggested that environments in which pupils felt able to talk with staff about "key learning issues" such as content of work, pace of work, assessment and so on were likely to be far more positive for staff and pupils alike. The free exchange of such information was also likely to lead to more appropriate and rapid interventions by teaching staff where problems were encountered.

Another participant made a similar point, suggesting that 'it helps, it's a lot easier if kids do that (give feedback)". He suggested that "a lot of kids don't have the guts to go 'see that, you're talking mince, I don't understand a word you're saying there"". This point was repeated by another participant, who indicated that the more feedback a pupil was willing to give, the more chance the teacher had of accurately evaluating their specific needs for support and the more useful such support would be. The element of 'surprise', in which a pupil who was presumed to be coping and therefore was allowed independence was found to be struggling, was avoidable only where the pupil was able provide feedback. However, a range of factors could hinder the flow of information, including low confidence, fear of admitting problems to the teacher, and fear of appearing inadequate. This was believed to be particularly true in Music at the more advanced levels, where peer respect and status were important factors that the child would not wish to jeopardize by making problems public.

\section{Level of motivation}

Motivation was identified as a significant factor of individual difference in seven of the eight Repertory Grids. During interview several participants suggested 
that the significance of high levels of motivation lay in ensuring that the pupil would be able to focus on tasks consistently and over long periods of time, thereby maximising learning and allowing the teacher freedom to work with others. One participant linked his perception of high motivation with the increased expectations he had of those pupils, suggesting that pupils whose motivation levels were high would be more likely to push themselves to high levels of achievement. Another stated that pupils with high motivation were a "scoosh" to teach, and that the teacher should not take credit for situations in which "the pupils would have managed without you". Conversely, another explained that pupils with low motivation required considerable attention from the teacher "so they actually do something". He suggested that this changed the nature of the teacher's task from educator to motivator, and could interfere with the former, which they considered more important. However, without sufficient motivation, there was little chance that learning would take place.

A number of participants also suggested that the need to ensure high levels of motivation obliged them to utilise a variety of teaching methods, recognising that certain learning environments (e.g. small groups) would be more suitable for certain pupils than for others. Finally, high motivation was linked with how enjoyable pupils were to teach. One participant stated that they "don't like working with people that aren't motivated”. 


\section{Level of confidence}

Several participants described variation in confidence as significant for teaching. This significance was related to the need for staff to encourage pupils at every opportunity, recognising achievement "however small", and by using peer group support to raise confidence. One participant related confidence to the requirement in music for pupils to share their work with others, and with the teacher. Where confidence to do this is lacking, the teacher's ability to effectively monitor the quality and content of work is limited.

\section{Levels of academic and general ability}

For one participant, academic ability had significant influence on the kinds of language they used with pupils. With more 'academic' or 'intelligent' pupils it was possible to discuss musical concepts and ideas in a more intellectual, mature manner, whereas with less intelligent pupils the teacher could not assume that they would understand anything other than the most basic terminology. This was echoed by others who found that the higher the level of academic ability, the less the chance of avoiding treating more complex topics in a cursory manner, because the teacher could assume that the pupil was able and willing to cope with the complexity of the work. This was particularly relevant at the upper stages of the secondary school. One participant discussed the situation where the explanation of musical notation and the temporal values of different notes were far easier in cases where the teacher could assume a basic understanding of mathematics. 
Participants did, however, stress that they saw no necessary relationship between high academic or general ability and high achievement in music.

\section{Semantic category 3: 'Contextual factors'}

Constructs were defined as contextual when they related to aspects of the pupil's experience that are environmentally or socially determined. The teacher, therefore, has limited opportunity to influence many of these. Nevertheless, in their grids participating teachers clearly believed that constructs of this type could be significant influences on their practice. Some of the ways in which this was described are indicated in the following section.

\section{Level of parental support}

Three participants identified variations in the level of parental support a child can expect as being significant influences in their teaching. Such variation could have a wide range of effects. Some of these related to the level of assistance the child would receive, such as help with homework and revision tasks, or in the case of the Music department the level of encouragement a child would receive to begin instrumental lessons. The significance of variations in support could also extend to the quality of the relationship between department and parent; one participant suggested that high-quality support from the parent could assist the department in aspects of its work such as reporting. In this participant's experience, pupils coming from supportive backgrounds would be more likely to have parents who attended parents' evenings, who wrote back to the department regarding written 
reports, and generally facilitated the reporting process. This was, he suggested, an important element in the child's education.

For another participant, quality of background support for learning was a significant influence on the extent to which pupils were motivated to 'better themselves'. Citing the case of 'Thomas', (one of the elements in her grid) who shared a number of features in terms of socio-economic status with other pupils, she concluded that it was the quality of support he had received from his parents that had enabled him to "pull himself forward" in music in a manner the others had not. The critical point, she suggested, came around the middle of the fourth year at secondary school, where for those lacking high-quality parental support, "the circumstances became too much".

The same participant was asked how knowledge of the quality of parental support influenced her teaching approach. In response, she suggested that knowledge of problematic home situations, where the child may be receiving little or no support, would cause her to "try to present a better, a different way of life". This could be accomplished, she suggested, by taking an interest in the pupil, encouraging them, giving them praise, and by "making experiences available to them" such as going to concerts. The participant noted, however, that the contact between pupil and teacher was relatively small, and that there would be long periods where "you have really little influence". She hoped that what she had done during the music class would "make some sort of impression". 


\section{Socio-economic status}

For one participant there was a clear relationship between SES and the quality of parental support the child received. Furthermore, perceptions of low SES could negatively affect the child's chances of receiving instrumental lessons. There was less chance, for example, of the pupil being allowed to take a musical instrument home to practice, as the teacher had no guarantee that it would return. Low SES pupils would generally not have access to a car, so the transportation of large instruments was impractical. Less affluent parents would be unable to provide their children with expensive musical instruments. The influence of this on the child's musical development was considered significant, as it meant the opportunities for practice were restricted to lunchtimes, after school and so on. The quality of progress would, unless motivation was high, suffer accordingly.

When questioned about the influence of this factor on teaching, she suggested that it was not the low SES in itself that was the problem, but that low SES appeared to be related to low self-esteem and low self-confidence, which in their view were significant factors of individual difference. Low SES pupils, she explained, frequently expected negative treatment, with the result that the teacher has to spend time developing confidence that they 'should' be spending on 'teaching'. Teachers, she suggested, had to be conscious of how they treated such pupils. This was particularly relevant in the area of expectations, where another participant explained; 
If I expect the same of kid from better backgrounds, if I expect the same as kids from poorer backgrounds, then I make the job harder for myself.

The effect of variations in SES on teacher expectations was also explored by another participant. Pupils from higher SES backgrounds, he believed, would often have the benefit of private tuition outside the school system;

So you're maybe expecting a greater background, a general knowledge, a head start, whereas you've more remedial work, more basic things to have to address with a pupil who comes from a low socio-economic background.

He went on to argue that SES influences "are not insurmountable, but they do play a very significant part". Following grid elicitation he indicated that only one pupil from those rated low on SES in the grid had "managed to rise above the situation", an achievement he attributed to positive peer influence and the social interactions that musical participation offered this individual.

For another participant, low SES was directly related to poor behaviour. For her, poverty and low SES was critical in determining pupil achievement and attainment in music, and as for other participants, had a direct influence on the expectations she had of her pupils.

\section{Level of attendance}

For one teacher, a pupil's level of attendance was a significant influence on their teaching. The significance of this in the context of music education was that "if they're not there, particularly in music, they're then not practicing instruments." This could result from their not having resources at home, or their missing the 
motivation and support the teacher would provide in the classroom. Additional problems could result, as absences would require the teacher to review and revisit work missed. The participant believed that some of these problems were particular to music, in that development in the practical aspects of music is most effective where it is continuous; "it's not something you dip into now and again". The participant therefore suggested that progress and attainment would be eroded where absence was significant.

\section{DISCUSSION}

This paper began by outlining the reasons why research into teachers' beliefs is important. One of the most compelling reasons for exploring such topics is that they help us understand the behaviour of classroom teachers, as their teaching is shaped fundamentally by what they think and believe both about their pupils and about the nature of learning and teaching. This study focussed on the former aspect, and attempted to investigate the Personal Construct models that a group of music teachers had of the pupils that they teach. In addition, the study went on to explore those teachers' descriptions of how such models of individual difference impact on their classroom approaches with those pupils, embracing the expectations, activities and types of communication that individual variations on specific constructs are believed to have.

The Personal Construct models elicited in this study focussed on the concept of individual differences between pupils. Teachers were encouraged to specify the 
ways in which they distinguish between different pupils, and to explain how those differences are important for their teaching. It was found that participants tended to contribute non-musical constructs, such as 'motivation' and 'speed of learning' rather than musical constructs such as 'musical ability' or 'musical skill'. However, it was clear from the semi-structured interviews, where participants were asked to describe how factors of individual difference influence their teaching, that musical differences are fundamentally important to teachers. The emergence of this finding was an indication of the strength of the mixed-methods design, where features of Personal Construct models could be explored and clarified during the interview phase. There is clearly a complex relationship at work between teachers' perceptions of pupils' individual differences, their models of how those differences interact with each other and in some cases are responsible for variations in factors, and how the teachers' perceptions of these factors in the individual pupil go on to shape their teaching. One of the key findings from the study is the interrelatedness of these various individual differences and the need for music educators to treat the pupil very much in terms of their individuality, taking into account their particular needs and requirements. This is particularly true where musical factors are believed to interact and influence other factors important for successful learning, such as 'confidence' and 'motivation'. Pupils with and without these attributes may require altogether different approaches from the teacher in order to achieve the same successful outcome. 
One clear finding from the study is that teachers take highly individual approaches to the kinds of personal construct models they develop with regard to individual differences. Grid analysis suggested that there was significant similarity in the method participants used to group pupils according to how they presented on a range of factors of individual difference, with an emphasis on high-middle-low types of grouping. There was, however, little evident consistency within these groupings on what those specific factors were. Generally, participants relied most heavily on factors that could be classified as cognitive, affective, and social to define their models, and less on contextual factors or subject-specific factors. They utilised a variety of constructs to differentiate between pupils who were otherwise similarly rated in terms of factors of individual difference. Variance in rating patterns could not be accounted for by a single unifying framework, but appeared to suggest one single component accounting for the majority of variance in how pupils were perceived. A second component, often using one or two constructs only, appeared to represent a more idiosyncratic method of differentiating between pupils.

Clearly, given the small sample used in this study much more research is required to determine whether the kinds of belief models and grouping patterns elicited are shared by music educators more generally. Also, it would be very useful to combine an elicitation of Personal Construct models relating to individual differences with observations of those teachers at work in their classrooms. The present study was limited to teachers' descriptions of the influence of their construct models on learning and teaching, and more empirical work in this 
context would be useful. Finally, developmental aspects of Personal Construct models should be investigated further to ascertain whether this particular form of 'teacher belief' is stable and consistent across the teaching career, or whether significant events are responsible for modifying or challenging the model currently held. 
Tuesday, 02 March 2021

\section{extra references}

Tan \& Hunter 2002:

http://vnweb.hwwilsonweb.com/hww/shared/shared_main.jhtml;jsessionid=TC4IJ 1OVSLQXNQA3DILCFF4ADUNGIIV0?_requestid=7803 